\title{
HUBUNGAN ANTARA DAERAH IDEAL UTAMA, DAERAH FAKTORISASI TUNGGAL DAN GELANGGANG NOETHERIAN
}

\author{
Eka Susilowati \\ Universitas PGRI Adibuana Surabaya \\ eka_s@unipasby.ac.id
}

\begin{abstract}
ABSTRAK
Setiap daerah ideal utama merupakan daerah faktorisasi tunggal, namun tidak berlaku sebaliknya. Ketidakberlakuan hubungan sebaliknya dari daerah faktorisasi tunggal dan daerah ideal utama dapat ditunjukkan dengan adanya contoh penyangkal. Hubungan ekuivalensi antara daerah ideal utama dan daerah faktorisasi tunggal dapat berlaku jika diberikan syarat cukup pada daerah faktorisasi tunggal. Syarat cukup yang diberikan pada daerah faktorisasi tunggal adalah daerah tersebut merupakan daerah Dedekind. Sedangkan ada juga hubungan antara daerah ideal utama dengan gelanggang Noetherian. Namun, hubungan antara daerah ideal utama dengan gelanggang Noetherian bukan hubungan ekuivalensi. Dalam artikel ini, juga dibahas hubungan daerah faktorisasi tunggal dengan gelanggang Noetherian. Hubungan antara daerah faktorisasi tunggal dan gelanggang Noetherian ini juga tidak berlaku hubungan ekuivalensi.
\end{abstract}

Kata kunci: daerah faktorisasi tunggal, daerah ideal utama, gelanggang Noetherian.

\begin{abstract}
Each principal ideal domain is a unique factorization domain, but does not apply otherwise. The absence of a relationship otherwise from a unique factorization domain and the principal ideal domain can be shown by the counter example. The equivalence relationship between a unique factorization domain and the principal ideal domain can apply if sufficient conditions are given ina unique factorization domain. The sufficient requirement given in the unique factorization domain is that the unique factorization domain is the Dedekind domain. Whereas there is also a connection between the principal ideal domain and the Noetherian ring. However, it is not an equivalent relationship. In this article, relationship of unique factorization domain and the Noetherian domain is also discussed. The relationship between the unique factorization domain and the Noetherian domain also does not have an equivalent relationship.
\end{abstract}

Keywords: unique factorization domain, principle ideal domain, Noetherian domain. 


\section{Eka Susilowati}

\section{PENDAHULUAN}

Dalam berbagai buku tentang aljabar abstrak, biasanya dijumpai suatu struktur aljabar yang dinamakan gelanggang. Menurut Hungerford, gelanggang didefinisikan sebagai himpunan struktur yang dilengkapi dengan dua operasi biner, yaitu penjumlahan dan pergandaan yang memenuhi beberapa aksioma (Hungerford, 1996). Gelanggang dengan unity yang bersifat komutatif dan tidak mempunyai pembagi nol disebut daerah integral.

Pada pertengahan abad 19, Kummer memperkenalkan suatu daerah integral dengan struktur khusus yang dinamakan daerah faktorisasi tunggal. Pada buku Milne (Milne, 2009), Kummer mendefinisikan bahwa suatu daerah integral dinamakan daerah faktorisasi tunggal jika setiap elemennya dapat difaktorisasi dalam bentuk hasil kali elemen tak tereduksi yang bersifat tunggal.

Selanjutnya, dikenal pula struktur daerah integral yang berbeda dengan daerah faktorisasi tunggal. Menurut Stein (Stein, 2012), apabila suatu daerah integral yang setiap ideal di dalamnya merupakan ideal utama maka daerah integral tersebut dinamakan daerah ideal utama.

Pada penelitian ini, diuraikan hubungan daerah ideal utama dan daerah faktorisasi tunggal. Adanya dugaan hubungan antara daerah ideal utama dengan daerah faktorisasi tunggal tidak berlaku hubungan ekuivalensi. Apabila diberikan suatu daerah ideal utama, akan diselidiki apakah setiap ideal prima di dalam daerah ideal utama tersebut merupakan ideal maksimal. Selanjutnya, akan diselidiki apakah daerah ideal utama merupakan gelanggang Noetherian.

\section{METODE PENELITIAN}

Dalam penelitian ini, definisi daerah ideal utama yang digunakan adalah daerah integral yang setiap ideal di dalamnya merupakan ideal utama. Selain itu, yang dimaksud, daerah faktorisasi tunggal adalah daerah integral yang memenuhi dua aksioma, yaitu setiap $p \in D-\{0\}$ bukan unit dapat dinyatakan sebagai hasil kali sejumlah berhingga elemen iredusibel dan jika $p_{1}, p_{2}, \ldots, p_{r}$ dan $q_{1}, q_{2}, \ldots, q_{s}$ dua macam faktorisasi dari suatu elemen $p \in D$ dengan $p_{i}, q_{i}$ elemen iredusibel maka $r=s$, dan apabila perlu dengan mengubah urutan, diperoleh $p_{i}$ berasosiasi 
dengan $q_{i}$. Pembahasan mengenai daerah ideal utama dan daerah faktorisasi tunggal dapat diperoleh diantaranya dalam buku Hungerford (Hungerford, 1996).

Hungerford juga memberikan contoh penyangkal bahwa tidak setiap daerah faktorisasi tunggal merupakan daerah ideal utama. Dalam perkembangannya, Stein memberikan sifat bahwa daerah integral yang mempunyai karakteristik seperti gelanggang Noetherian (Stein, 2012).

Daerah ideal utama memiliki sifat khusus. Sifat tersebut berkaitan dengan ideal prima dan ideal maksimal sebagaimana terdapat dalam proposisi berikut:

Proposisi 1 (Hungerford, 1996)

Jika D adalah daerah ideal utama, maka setiap ideal prima tak nol I adalah ideal maksimal.

\section{Bukti :}

Diambil sebarang ideal prima $I$ dari $D$. Andaikan $I$ bukan ideal maksimal dalam $D$ berarti ada ideal sejati $J$ dengan $I \subseteq J$ di $D$. Karena $D$ adalah daerah ideal utama maka $I=\langle a\rangle$ dan $J=\langle b\rangle$ untuk suatu $a, b \in D$. Ambil $a \in J$ maka $a=r b=s a b=a s b$. Karena $D$ merupakan daerah integral maka berdasarkan Proposisi tentang hukum kanselasi diperoleh $1=s b$. Akibatnya $J=\langle b\rangle=D$ maka kontradiksi dengan pengandaian.Oleh karena itu, $I$ ideal maksimal. $\square$

Setiap anggota dalam daerah ideal utama ternyata dapat dinyatakan sebagai hasil kali elemen ireduksibel.

\section{Teorema 2}

Diberikan $D$ daerah ideal utama dan $a \in D-\{0\}$, a bukan unit. Setiap elemen a dapat dinyatakan sebagai hasil kali elemen-elemen iredusibel.

\section{Bukti}

Diambil $a \in D-\{0\}, a$ bukan unit. Akan ditunjukkan a dapat difaktorisasi sebagai hasil kali elemen iredusibel di dalam $D$. Jika $a$ merupakan elemen iredusibeldi dalam $D$ maka bukti selesai. Misalkan $a$ merupakan bukan elemen iredusibel di dalam $D$, maka $a=a_{1} b_{1}$ untuk suatu $a_{1}, b_{1} \in D$ dan keduanya bukan 
unit. Berdasarkan Teorema 2.4.9 diperoleh $\langle a\rangle \subset\left\langle a_{1}\right\rangle$. Jika $\langle a\rangle=\left\langle a_{1}\right\rangle$ maka $a$ dan $a_{1}$ berasosiasi sehingga $b_{1}$ merupakan unit. Kontradiksi. Jadi $\langle a\rangle \neq\left\langle a_{1}\right\rangle$. Jika $a_{1}$ iredusibel maka bukti selesai. Misalkan $a_{1}$ bukan elemen iredusibel, maka $a_{1}=a_{2} b_{2}$ untuk suatu $a_{2}, b_{2} \in D$ dan keduanya bukan unit. Berdasarkan Teorema 2.6.9 diperoleh $\left\langle a_{1}\right\rangle \subset\left\langle a_{2}\right\rangle$ dan $\left\langle a_{1}\right\rangle \neq\left\langle a_{2}\right\rangle$. Apabila proses dilanjutkan, maka akan terbentuk rangkaian naik ideal-ideal di $D$ yaitu $\langle a\rangle \subset\left\langle a_{1}\right\rangle \subset\left\langle a_{2}\right\rangle \subset \ldots$. Berdasarkan Teorema 2.4.8, haruslah terdapat $r \in Z^{+}$sehingga $\left\langle a_{r}\right\rangle=\left\langle a_{s}\right\rangle$ untuk setiap $s \geq r$. Oleh karena itu, $a_{r}$ harus merupakan elemen iredusibel. Hal ini menunjukkan bahwa a mempunyai hasil kali dua dengan salah satu faktornya merupakan elemen iredusibel di dalam $D$.

Misalkan $a=p_{1} c_{1}$ dengan $p_{1}$ elemen iredusibel dan $c_{1}$ bukan merupakan unit. Karena $c_{1} \mid a$ maka berdasarkan Teorema 2.4.9 $\left\langle a_{1}\right\rangle \subset\left\langle c_{1}\right\rangle$ dengan $\left\langle a_{1}\right\rangle \neq\left\langle c_{1}\right\rangle$. Jika $c_{1}$ merupakan elemen iredusibel di dalam $D$ maka bukti selesai. Misalkan $c_{1}$ bukan merupakan elemen iredusibel di dalam $D$, maka $c_{1}=p_{2} c_{2}$ dengan $p_{2}$ elemen iredusibel dan $c_{2}$ bukan merupakan unit. Akibatnya $\left\langle c_{1}\right\rangle \subset\left\langle c_{2}\right\rangle$ dengan $\left\langle c_{1}\right\rangle \neq\left\langle c_{2}\right\rangle$. Apabila proses dilanjutkan, maka akan terbentuk rangkaian naik idealideal di $D$ yaitu $\langle a\rangle \subset\left\langle c_{1}\right\rangle \subset\left\langle c_{2}\right\rangle \subset \ldots$. Berdasarkan Teorema 2.4.8, haruslah terdapat $r \in \square^{+}$sehingga $\left\langle c_{r}\right\rangle=\left\langle c_{s}\right\rangle$ untuk setiap $s \geq r$. Akibatnya $c_{r}$ harus merupakan elemen iredusibel di dalam $D$. Jadi $a=p_{1} p_{2} \ldots p_{r} c_{r}$ dengan $p_{i}$ untuk setiap $i$ dan $c_{r}$ elemen-elemen iredusibel di dalam $D$

Berikut ini sifat lain dari daerah ideal utama. Anggota dari daerah ideal utama yang iredusibel memiliki sifat yang berhubungan dengan habis dibagi.

\section{Teorema 3}

Diberikan $D$ daerah ideal utama dan $p, a, b \in D$. Jika $p$ iredusibel di dalam $D$ dan $p \mid$ ab maka $p \mid a$ atau $p \mid b$.

\section{Bukti}


Diketahui $p$ iredusibel di dalam $D$ dan $p \mid a b$. Menurut Definisi 2.1.1.12, maka terdapat $d \in D$ sehingga $a b=d p$. Akibatnya $a b \in\langle p\rangle$. Berdasarkan Teorema 2.4.11, maka $\langle p\rangle$ merupakan ideal maksimal. Kemudian menurut Teorema 2.3.3.7, $\langle p\rangle$ merupakan ideal prima. Karena $\langle p\rangle$ merupakan ideal prima dan $a b \in\langle p\rangle$ maka $a \in\langle p\rangle$ atau $b \in\langle p\rangle$. Jika $a \in\langle p\rangle$ maka terdapat $d \in R$ sehingga $a=p d$. Dengan demikian, $p \mid a$. Jika $b \in\langle p\rangle$ maka terdapat $e \in D$ sehingga $b=p e$. Akibatnya $p \mid b$. Dengan demikian, jika $p \mid a b$ maka $p \mid a$ atau $p \mid b . \square$

Berikut ini akibat dari Teorema 3 yang diperumum.

\section{Akibat 4}

Diberikan $D$ daerah ideal utama dan $p \in D$ elemen iredusibel. Jika $p \mid a_{1} a_{2} \ldots a_{n}$ dengan $a_{i} \in R$ maka $p \mid a_{i}$ untuk paling sedikit satu nilai $i$.

\section{Bukti}

Diketahui $p \in D$ elemen iredusibel di dalam $D$ dan $p \mid a_{1} a_{2} \ldots a_{k}$. Dengan menggunakan induksi matematika pada $n$, untuk $n=1$ maka jelas terbukti. Selanjutnya, untuk $n=2$ maka berdasarkan Teorema 2.4 .12 terbukti $p$ habis membagi salah satu faktornya. Diasumsikan benar untuk $n=k-1$ bahwa $p \mid a_{i}$ untuk paling sedikit satu nilai $i$ dengan $i=1,2, \ldots, k-1$. Akan ditunjukkan untuk $n=k$. Karena $p \mid\left(a_{1} a_{2} \ldots a_{k-1}\right) a_{k}$ maka berdasarkan asumsi, $p \mid a_{i}$ untuk paling sedikit satu nilai $i$ dengan $i=1,2, \ldots, k-1$. Sehingga terbukti benar untuk $n=k$.

Selanjutnya, diberikan definisi gelanggang dengan karakteristik khusus yang dinamakan gelanggang Noetherian.

\section{Definisi 5}

Jika $R$ adalah gelanggang dan setiap rangkaian naik ideal-ideal di dalam $R$ yaitu $I_{1} \subset I_{2} \subset \ldots$ terdapat $r$ sedemikian sehingga $I_{r}=I_{s}$ untuk setiap $s \geq r$ maka $R$ dinamakan gelanggang Noetherian. 


\section{Eka Susilowati}

Berikut ini karakteristik dari gelanggang Noetherian.

\section{Teorema 6}

Jika $R$ gelanggang maka pernyataan berikut ekuivalen :

1) $R$ Noetherian.

2) Setiap koleksi tak kosong dari ideal-ideal di $R$ mempunyai elemen maksimal.

3) Setiap ideal di $R$ dibangun secara berhingga.

\section{Bukti}

1) $\Rightarrow 2$ ) Andaikan $S=\left\{I_{\alpha}\right\}_{\alpha \in A}$ himpunan tak kosong ideal-ideal di $R$ yang tidak mempunyai elemen maksimal. Ambil $I_{1} \in S$, karena $S$ tidak mempunyai elemen maksimal maka terdapat $I_{2} \in S$ sedemikian sehingga $I_{1} \subset I_{2}$ dengan $I_{1} \neq I_{2}$. Selanjutnya karena $I_{2} \in S$ maka terdapat $I_{3} \in S$ sehingga $I_{2} \subset I_{3}$ dengan $I_{2} \neq I_{3}$. Proses dilanjutkan, sehingga terbentuk rangkaian naik ideal-ideal di $R$ yaitu $I_{1} \subset I_{2} \subset \ldots$ Karena $R$ Noetherian maka terdapat $r$ sedemikian sehingga $I_{r}=I_{s}$ untuk setiap $s \geq r$. Ini berarti $S$ memuat elemen maksimal sehingga kontradiksi dengan definisi himpunan $S$. Sehingga himpunan $S$ tidak ada dan terbukti bahwa setiap himpunan tak kosong dari ideal-ideal $R$ memuar elemen maksimal.

2) $\Rightarrow 3$ ) Ambil sebarang $I$ ideal dari $R$. Akan ditunjukkan bahwa $I$ merupakan ideal yang dibangun secara berhingga. Misalkan $T=\{J \mid J$ ideal dari $R$ dibangun secara berhingga dan $J \subset I\}$. Jelas bahwa $T$ bukan himpunan kosong karena $\{0\} \in T$. Berdasarkan 2), terdapat elemen maksimal katakan $J_{k} \in T$ untuk suatu $k \in Z^{+}$. Ambil sebarang $a \in I$ dan bentuk $J_{k}+\langle a\rangle$. Karena $J_{k} \in T$ dan $\langle a\rangle \in T$ maka $J_{k}+\langle a\rangle \in T$. Perhatikan bahwa $J_{k} \subset J_{k}+\langle a\rangle$, padahal $J_{k} \in T$ merupakan elemen maksimal maka $J_{k}=J_{k}+\langle a\rangle$. Oleh karena itu, $a \in J_{k}$. Karena $a \in I$ diambil sebarang maka $I \subset J_{k}$. Tetapi $J_{k} \in T$ maka $J_{k} \subset I$. Hal ini berakibat $I=J_{k}$ sehingga $I \in T$.

$3) \Rightarrow 1)$ Diambil sebarang rangkaian naik ideal - ideal di $R$. Misalkan $I_{1} \subset I_{2} \subset \ldots$ dan namakan $I=\bigcup_{i} I_{i}$. Maka $I$ juga ideal dalam $R$. Berdasarkan 
$3)$, terdapat $a_{1}, a_{2}, \ldots, a_{r} \in R$ sedemikian sehingga $I=\left\langle a_{1}, a_{2}, \ldots, a_{r}\right\rangle$. Karena $a_{1}, a_{2}, \ldots, a_{r} \in I=\bigcup_{i} I_{i}$ maka terdapat bilangan bulat positif $t$ sedemikian sehingga $a_{i} \in I_{t}$ untuk setiap $i=1,2, \ldots, k$. Tetapi karena $I_{1} \subset I_{2} \subset \ldots$ maka terdapat $r$ sedemikian sehingga $a_{i} \in I_{r}$ untuk semua $i$. Akibatnya untuk semua $s \geq r$ diperoleh $I=\left\langle a_{1}, a_{2}, \ldots, a_{r}\right\rangle \subset I_{r} \subset I_{s} \subset I=\left\langle a_{1}, a_{2}, \ldots, a_{r}\right\rangle$. Jadi $I_{r}=I_{s}=I$ untuk setiap $s \geq r$. Dengan kata lain, $R$ merupakan gelanggang Noetherian. $\square$

Definisi berikut merupakan definisi daerah integral yang dilengkapi dengan tiga sifat khusus.

\section{Definisi 7}

Daerah integral D disebut daerah Dedekind (Dedekind domain) jika gelanggang Noetherian, tertutup secara integral dalam lapangan hasil baginya, dan ideal prima tak nol dari D merupakan ideal maksimal.

\section{HASIL PENELITIAN DAN PEMBAHASAN}

\section{Hubungan Antara Daerah Ideal Utama dan Daerah Faktorisasi Tunggal}

Hungerford dalam bukunya menyatakan bahwa setiap daerah ideal utama merupakan daerah faktorisasi tunggal (Hungerford, 1996). Sifat ini tidak berlaku sebaliknya dengan memberikan contoh penyangkal. Berikut teorema yang menjelaskan hubungan daerah ideal utama dan daerah faktorisasi tunggal dalam buku Hungerford.

Teorema 8 (Hungerford, 1996)

Setiap daerah ideal utama merupakan daerah faktorisasi tunggal.

\section{Bukti}

Berdasarkan Teorema 2, telah dibuktikan syarat pertama dari daerah faktorisasi tunggal. Maka untuk menunjukkan daerah ideal utama merupakan daerah faktorisasi tunggal, cukup dibuktikan syarat kedua terpenuhi yaitu faktorisasi dalam daerah ideal utama adalah tunggal sebagai berikut: 


\section{Eka Susilowati}

Ambil sebarang $a \in D-\{0\}, a$ bukan unit. Misalkan $a$ dapat difaktorisasikan menjadi $a=p_{1} p_{2} \ldots p_{r}$ dan $a=q_{1} q_{2} \ldots q_{s}$ dengan $p_{i}, q_{i}$ elemen-elemen iredusibel di dalam $D$. Maka $p_{1} \mid\left(q_{1} q_{2} \ldots q_{s}\right)$. Berdasarkan Akibat 4, $p_{1} \mid q_{j}$ untuk suatu $j \in Z^{+}$. Apabila diperlukan dengan mengubah urutan, sehingga dapat diasumsikan $j=1$, sehingga $p_{1} \mid q_{1}$. Oleh karena itu, $q_{1}=p_{1} u_{1}$ untuk suatu $u_{1} \in D$. Karena $p_{i}, q_{i}$ elemen iredusibel maka $u_{1}$ merupakan unit di dalam $D$. Dengan demikian, $p_{1}$ dan $q_{1}$ berasosiasi di dalam $D$, sehingga diperoleh $p_{1} p_{2} \ldots p_{r}=p_{1} u_{1} q_{2} \ldots q_{s}$. Karena $D$ daerah integral, maka berlaku hukum kanselasi sehingga diperoleh $p_{2} \ldots p_{r}=u_{1} q_{2} \ldots q_{s}$. Apabila proses tersebut dilanjutkan, maka diperoleh $1=u_{1} u_{2} \ldots u_{r} q_{r+1} \ldots q_{s}$. Karena $q_{r+1}, q_{r+2}, \ldots, q_{s}$ elemen iredusibel maka $q_{1} q_{2} \ldots q_{s}$ bukan unit di dalam $D$. Padahal $u_{1} u_{2} \ldots u_{r}\left[q_{r+1} q_{r+2} \ldots q_{s}\right]=1$, maka haruslah $r=s$. Oleh karena $u_{i}$ unit di dalam $D$ maka $p_{i}$ berasosiasi dengan $q_{i}$ di dalam $D$. Dengan demikian, syarat kedua daerah faktorisasi tunggal terpenuhi. Karena syarat pertama daerah faktorisasi tunggal telah terpenuhi pada pembuktian Teorema 2 maka terbukti daerah ideal utama merupakan daerah faktorisasi tunggal. $\square$

Selanjutnya, diselidiki hubungan sebaliknya. Adanya dugaan bahwa tidak berlaku hubungan sebaliknya. Pada artikel ini diberikan contoh penyangkal yaitu contoh yang merupakan daerah faktorisasi tunggal namun bukan daerah ideal utama.

\section{Teorema 9}

Jika $D$ daerah faktorisasi tunggal maka $D[x]$ merupakan daerah faktorisasi tunggal.

Berdasarkan Teorema 9 dapat diberikan contoh daerah polinimial yang merupakan daerah faktorisasi tunggal. Himpunan $Z$ merupakan daerah faktorisasi tunggal, maka $Z[x]$ merupakan daerah faktorisasi tunggal. Namun, $Z[x]$ bukan merupakan daerah ideal utama. 


\section{Proposisi 10}

$Z[x]$ bukan merupakan daerah ideal utama.

Dari hasil penelitian ini, akan dibuktikan bahwa hubungan ekuivalensi antara daerah ideal utama dan daerah faktorisasi tunggal tidak berlaku. Dalam (Osserman, 2011), (Chow, 2011), (Milne, 2009), dan (Bosman, 2011) memberikan syarat cukup agar hubungan ekuivalensi daerah ideal utama dan daerah faktorisasi tunggal dapatberlaku.

Proposisi 11 (Hungerford, 1996)

Diberikan D daerah Dedekind. D daerah ideal utama jika dan hanya jika D daerah faktorisasi tunggal.

\section{Hubungan Antara Daerah Ideal Utama dan Gelanggang Noetherian}

Hubungan selanjutnya yang akan dibahas adalah mengenai hubungan antara daerah ideal utama dan gelanggang Noetherian.

Proposisi 12 (Hungerford, 1996)

Setiap daerah ideal utama D merupakan gelanggang Noetherian.

\section{Hubungan Antara Daerah Faktorisasi Tunggal dan Gelanggang Noetherian}

Hubungan searah antara daerah faktorisasi tunggal dengan gelanggang Noetherian belum tentu berlaku. Hubungan tersebut berlaku jika daerah faktorisasi tunggalnya memiliki syarat cukup.

\section{Proposisi 13}

Diberikan $D$ daerah Dedekind. Jika $D$ daerah faktorisasi tunggal maka D merupakan gelanggang Noetherian.

\section{SIMPULAN}

Secara garis besar, di dalam penelitian ini dapat disimpulkan bahwa tidak berlaku hubungan ekuivalensi daerah ideal utama dan daerah faktorisasi tunggal. 
Setiap daerah ideal utama merupakan gelanggang Noetherian. Setiap $D$ daerah faktorisasi tunggal merupakan gelanggang Noetherian jika $D$ merupakan daerah Dedekind.

\section{DAFTAR PUSTAKA}

Bosman, J. (2011). Algebraic Number Theory. Bounyer.

Chow, S. (2011). Thesis: An Introduction ri Algebraic Number Theory, and the Class Number Formula. Melbourne, Australia: University of Melbourne.

Hungerford, T. W. (1996). Abstract Algebra: An Introduction. Saunders College Publishing.

Milne, J. S. (2009). Algebraic Number Theory. New Zealand.

Osserman, B. (2011). Algebraic Number Theory. Bouyer.

Stein, W. (2012). Algebraic Number Theory, A Computational Approach. William Stein. 